\title{
Oxygen/Carbon Ratio Effects on Surface-Modified Carbon Nanotubes
}

\author{
U.S. Chen ${ }^{1, a}$, H.Y. Su${ }^{1}$, C.H. Wang ${ }^{1}$, Han C. Shih ${ }^{1,2 . b}$, C.T. Hsieh ${ }^{3}$, and \\ J.M. Chen ${ }^{4}$ \\ ${ }^{1}$ Department of Materials Science and Engineering, National Tsing Hua University, 101, Sec. 2 \\ Kuang Fu Rd., Hsinchu 300, Taiwan \\ ${ }^{2}$ Institute of Materials Science and Nanotechnology, Chinese Culture University, 55, Hwa-Kang Rd., \\ Yang-Ming-Shan, Taipei 111, Taiwan \\ ${ }^{3}$ Department of Chemical Engineering and Materials Science, Yuan Ze University, 135, Tuan- Tung \\ Rd., Chungli, Taoyuan 320, Taiwan \\ ${ }^{4}$ Materials Research Laboratory, Industrial Technology Research Institute, 195, Sec. 4, Chung \\ Hsing Rd., Chutung, Hsinchu 310, Taiwan

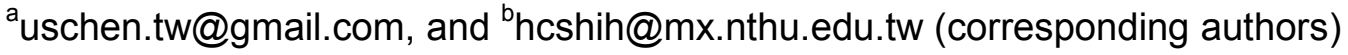

received paper 5.11.2007, received revised paper, 16.12.2007 accepted date, 20.12.2007

Keywords: Carbon nanotube; Surface modification; Self-assembled; Oxygen/carbon ratio

\begin{abstract}
Carbon nanotubes (CNTs) were functionalized using a simple method of heat treatment under oxygen atmosphere followed by an immersion in a tin nitrate aqueous solution. And well-dispersed $\mathrm{SnO}_{\mathrm{x}}$ nanodots were decorated on the surface of CNTs. X-ray photoelectron spectroscopy (XPS) analysis showed that the $\mathrm{O} / \mathrm{C}$ ratio increases with oxygen-treated time. The distribution of carbon-containing functional groups on the $\mathrm{CNTs}$ surface, i.e., $\mathrm{C}-\mathrm{C}, \mathrm{C}-\mathrm{O}, \mathrm{C}=\mathrm{O}$, $\mathrm{O}-\mathrm{C}=\mathrm{O}$, and $\pi-\pi^{*}$ shake up bonds can be identified and deconvoluted by a symmetrical Gauss function. The contact angle of $\mathrm{H}_{2} \mathrm{O}$ and CNTs is dependent on $\mathrm{O} / \mathrm{C}$ ration. The relationships between the fraction of carbon-containing functional groups and various oxygen treatment times are also discussed.
\end{abstract}

\section{Introduction}

Carbon nanotubes/nanofibers (CNTs/CNFs) have been attracting a great deal of attention for their unique mechanical, electronic, transport, thermal, and vibrational properties [1]. To make further manipulation and application in various technological areas such as gas adsorbents, templates, actuators, catalyst supports, probes, composite reinforcements, chemical sensors [2-6], etc., surface modification with specific functionalities onto the surface of CNTs is to be of great urgency. Some methods for synthesizing carbon-containing hybrid materials have been developed, such as $\mathrm{InP} / \mathrm{C}$ composite nanowires via the vapor-solid process [7], carbon nanofibers reinforced ceramic matrix composites via dry pressing [8], and cadmium sulphide nanoparticles on the CNTs via an in situ synthesis [9]. Otherwise, various semiconductor nanoparticles such as cadmium selenide, zinc sulphide, silicon dioxide, and titanium dioxide were formed on the surface of the CNTs [10-13].

Specific functional groups such as $\mathrm{C}-\mathrm{O}, \mathrm{C}=\mathrm{O}$, and $\mathrm{O}-\mathrm{C}=\mathrm{O}$ can be attached on the surface of $\mathrm{CNTs}$ by surface modification. Gogotsi et al. reported that functional groups implanted in the defect sites of the sidewall of CNTs [14]. These polarized functional groups could be interacted with $\mathrm{H}_{2} \mathrm{O}$ molecules that dramatically change the CNTs' surface property from hydrophobic to hydrophilic. After functionalizing, metal oxides can be bonded on the surface of CNTs via the ionic exchange in an aqueous solution of metal nitrate. 
The reactive sites for the bonding of oxygen-containing groups are provided from the vacancies and/or the disordered sections of the CNTs. Therefore, the phenomenon of the $\mathrm{O} / \mathrm{C}$ ratio relying on the thermal oxidation should be the function of the treatment time, ambiance, temperature, and disorder degree of CNTs. The pristine CNTs and the following thermal oxidation temperature were fixed. Under various heat treatment time, different oxidation level and/or different distribution of the functional groups created on the surface of CNTs are expected. The chemistry of the CNTs coupled with the metal ionics in the aqueous phase, thus forming a self-assembled interaction. By the ionic exchange between metal ions in aqueous and specific functional groups of CNTs, functional groups provide the binding sites to exchange hydrogen ions for metal ions. Finally, thermal treatment was performed to solidify the decorated $\mathrm{SnO}_{\mathrm{x}}$ nanodots on CNTs. In this work, surface functionalizing for the fabrication of $\mathrm{SnO}_{\mathrm{x}}$ nanodots/CNTs hybrid materials, composition and distribution of the functional groups, and ionic interaction are discussed.

\section{Experimental}

The CNTs used in this work were synthesized via a thermal-chemical vapor-deposition process using Ni nanoparticles as the catalyst. The carbon source gas, ethylene, mixed with the inert gas, Ar, were introduced to a furnace at $700{ }^{\circ} \mathrm{C}$ for $60 \mathrm{~min}$ to obtain the CNTs. Nickel catalysts embedded in CNTs were removed thoroughly by chemical etching using hydrochloric acid. Then, the CNTs were rinsed repeatedly by deionized water for cleaning. After vacuum-drying, the CNTs were then oxidized by a thermal treatment at $250{ }^{\circ} \mathrm{C}$ under an oxygen atmosphere for $0,5,60$, and $300 \mathrm{~min}$, named as $\mathrm{CN} 0, \mathrm{CN} 5, \mathrm{CN} 60$, and $\mathrm{CN} 300$. Under the condition, carbon vaporization is negligible and the weight gain is due to the oxygen chemisorption, instead of the weight loss observed in the oxidation [15].

The post-oxidized CNTs, each weighted $0.1 \mathrm{~g}$, were made as a flake by loading a pressure of 5 ton, in which a drop of deionized water $(5 \mu \mathrm{L})$ was dripped down for contact angle measurement. Also, the samples CN0, CN5, CN60, and CN300, each weighted $0.1 \mathrm{~g}$, were mixed in $0.1 \mathrm{M}$ tin (IV) nitrate (99 $\%$, Alfa) solution, sonicated for $10 \mathrm{~min}$ and stirred at room temperature for one day. The CNTs bonded with tin ions were then filtered from the solution. After filtering, the treated samples were heated at $450{ }^{\circ} \mathrm{C}$ under an argon atmosphere for $1 \mathrm{hr}$. The purpose of which is to reinforce the infrastructure.

The samples were sonicated in ethanol and deposited on carbon-coated copper grids for transmission electron microscopy (TEM) characterization. The morphology of the nanoparticles decorated CNTs was performed by field emission (FE-TEM, JEOL JEM-2100F) operating at $200 \mathrm{kV}$ with a lattice resolution of $0.1 \mathrm{~nm}$. To investigate the chemisorptions of the species on the surface of the CNTs, the X-ray photoelectron spectroscopy (XPS, JEOL 4320) with a Mg Ka source (B.E. = $1343 \mathrm{eV}$ ) was employed to examine the chemical-bonding nature and categories.

\section{Results and discussion}

The broad C1s peak ranged from 280 to $297 \mathrm{eV}$ in the XPS spectra may be composed of peaks contributed by the binding of several carbon-base functional groups and was deconvoluted using a peak-synthesis procedure in which the Gaussian function is assumed to fit each component. All sub-peaks of core-level spectra were fitted with the same value $(1.8 \mathrm{eV})$ for the full width at half-maximum (FWHM). The $\mathrm{O} / \mathrm{C}$ ratios were obtained by integrating the core level peak area of $\mathrm{O}(1 \mathrm{~s})$ and $\mathrm{C}(1 \mathrm{~s})$, corrected by atomic sensitivity factors based on the empirical peak-area values $[16,17]$ modified for the system's transmission function, as shown in Fig. 1. These peaks are identified as $\mathrm{C}-\mathrm{C}$ at $283.7 \mathrm{eV}, \mathrm{C}-\mathrm{O}$ at $285.2 \mathrm{eV}, \mathrm{C}=\mathrm{O}$ at $286.7 \mathrm{eV}, \mathrm{O}-\mathrm{C}=\mathrm{O}$ at $288.6 \mathrm{eV}$, and $\pi-\pi^{*}$ shake up bonds at $290.7 \mathrm{eV}$. Similar results were reported by Tang et al., claiming that oxygen-containing functional groups were created on the surface of activated carbon fibers by oxygen 
plasma treatment [18]. The distributions of the binding functional groups are listed in Table 1, which were calculated by integrating the peak area. With the increasing of the oxygen treatment time, the $\mathrm{O} / \mathrm{C}$ ratio increases from 0.23 to 2.77 (Table. 1). Furthermore, the fraction of $\mathrm{C}-\mathrm{C}$ bonds and $\pi-\pi^{*}$ shake up bonds decrease with the increasing oxidation time; while the increase of oxygen content upon oxidation is being resulted mainly by the formation of the $\mathrm{C}-\mathrm{C}$ and $\mathrm{C}=\mathrm{O}$ groups (Table. 1).
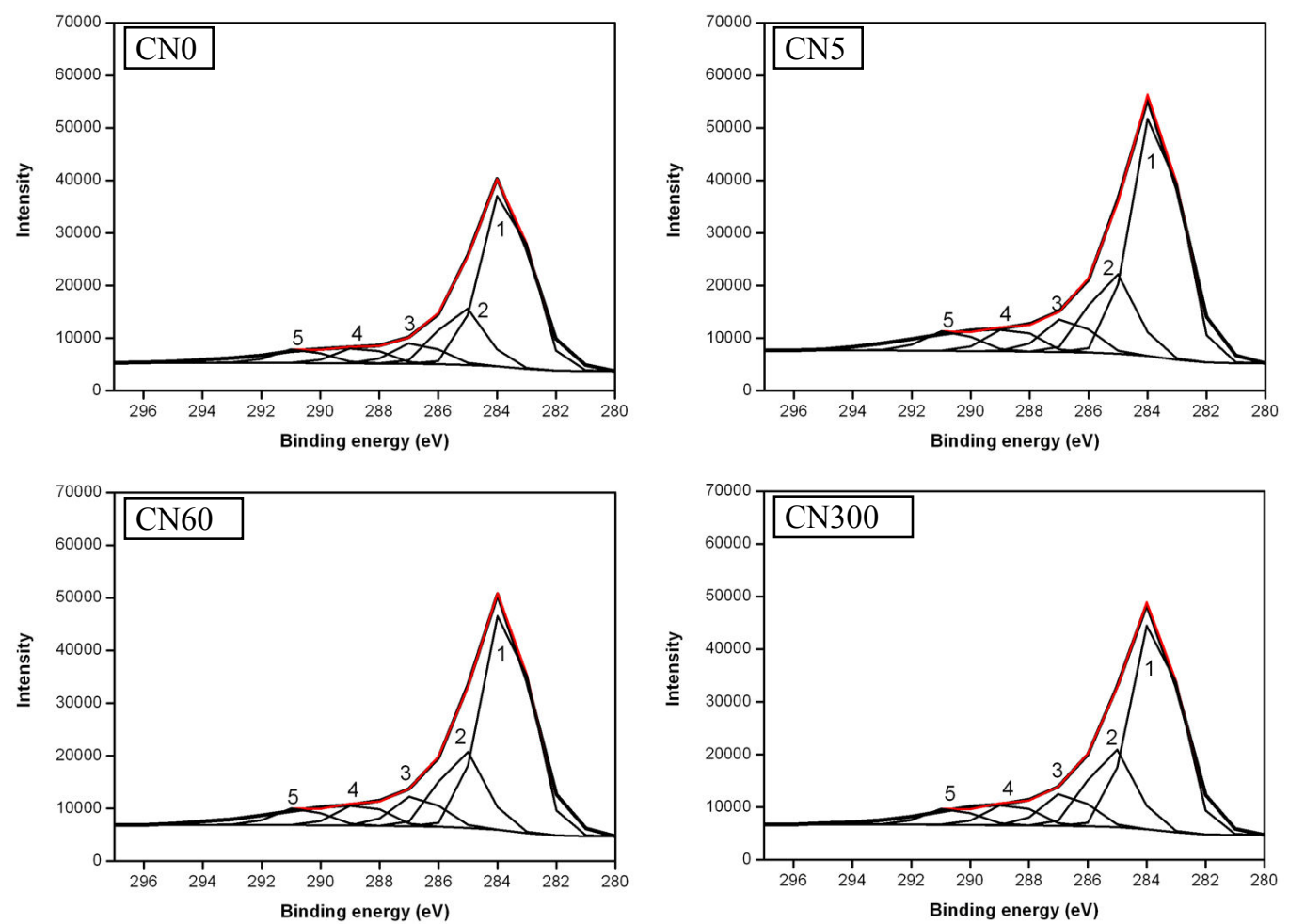

Fig. 1. C1s core level spectra and deconvoluted peaks of CN0, CN5, CN60, and CN300. The full-width at half-maximum of each component is maintained as $1.8 \mathrm{eV}$.

Table $1 . \mathrm{O} 1 \mathrm{~s} / \mathrm{C} 1 \mathrm{~s}$ ratio and carbon-containing functional group distribution determined from deconvolution of XPS spectra.

\begin{tabular}{lcccccc}
\hline Sample & & $\mathrm{O} 1 \mathrm{~s} / \mathrm{C} 1 \mathrm{~s}$ & \multicolumn{3}{c}{ Functional group distribution (\%) } \\
\cline { 2 - 7 } & & $\mathrm{C}-\mathrm{C}$ & $\mathrm{C}-\mathrm{O}$ & $\mathrm{C}=\mathrm{O}$ & $\mathrm{O}-\mathrm{C}=\mathrm{O}$ & $\pi-\pi^{*}$ \\
\hline CN0 & 0.23 & 63.12 & 19.1 & 7.26 & 5.49 & 5.04 \\
CN5 & 0.82 & 62.09 & 19.04 & 8.09 & 5.68 & 5.1 \\
CN60 & 1.48 & 61.41 & 19.97 & 8.16 & 5.71 & 4.75 \\
CN300 & 2.77 & 58.82 & 21.34 & 9.37 & 5.85 & 4.62 \\
\hline
\end{tabular}

In order to further confirm whether the oxygen-containing function groups were attached onto CNTs, a contact angle measurement was employed based on the hydrophilic property of polarized functionalities with water. Figure 2 shows the relationship between contact angle and $\mathrm{O} / \mathrm{C}$ ratio. The contact angle decreases from 120 degree $(\mathrm{O} / \mathrm{C}=0.23)$ to 95 degree $(\mathrm{O} / \mathrm{C}=2.77)$. As the $\mathrm{O} / \mathrm{C}$ ratio increases, the contact angle decreases, expectably, indicating that more oxygen content would enhance the surface of CNTs to be hydrophilic. It is consistent with the results shown in Table 1. 
After immersing in tin (IV) nitrate solution for one day, nanodots decorated CNTs were formed and examined by XPS. Both intensities of O1s and Sn3d increase with post-oxygen treatment time, as shown in Fig. 3. By the peak-area analysis from the XPS spectra, the atomic concentrations from the surface of CNTs can be quantified, including $\mathrm{O} 1 \mathrm{~s}, \mathrm{C} 1 \mathrm{~s}$, and $\mathrm{Sn} 3 \mathrm{~d}_{5 / 2}$ are listed in Table 2. During the oxidation procedure, the fraction of $\mathrm{Sn}$ increases with the thermal treatment time, which reflects the fact that surface-oxidized functional groups provide stronger interaction between the tin ions and oxygen on the surface of CNTs. Oxygen-containing functional groups form a hydrophilic and polarized surface that is capable of facilitating the surface affinity to the polarized molecules such as metal ions and water molecules. Polar functional groups, such as carboxyl and carbonyl-functional groups, act as significant roles for the interaction with the tin ions.

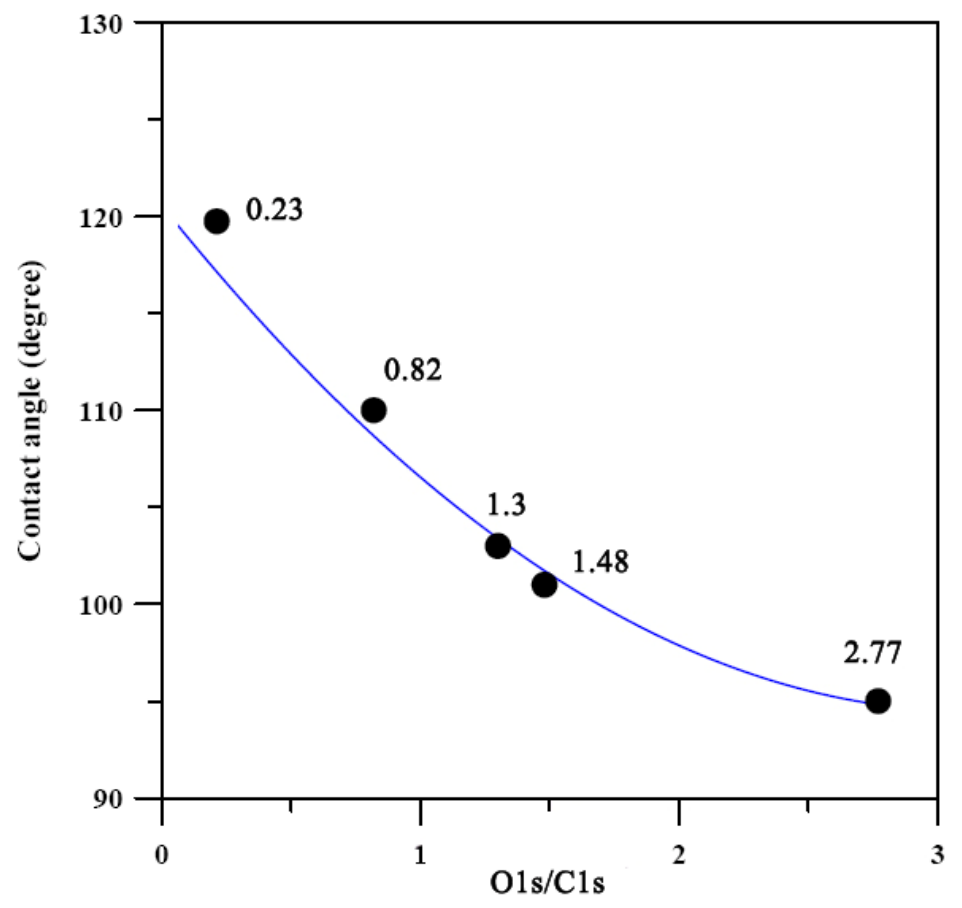

Fig. 2. $\mathrm{O} 1 \mathrm{~s} / \mathrm{C} 1 \mathrm{~s}$ ratio at various oxygen-treated times vs. water contact angle. 

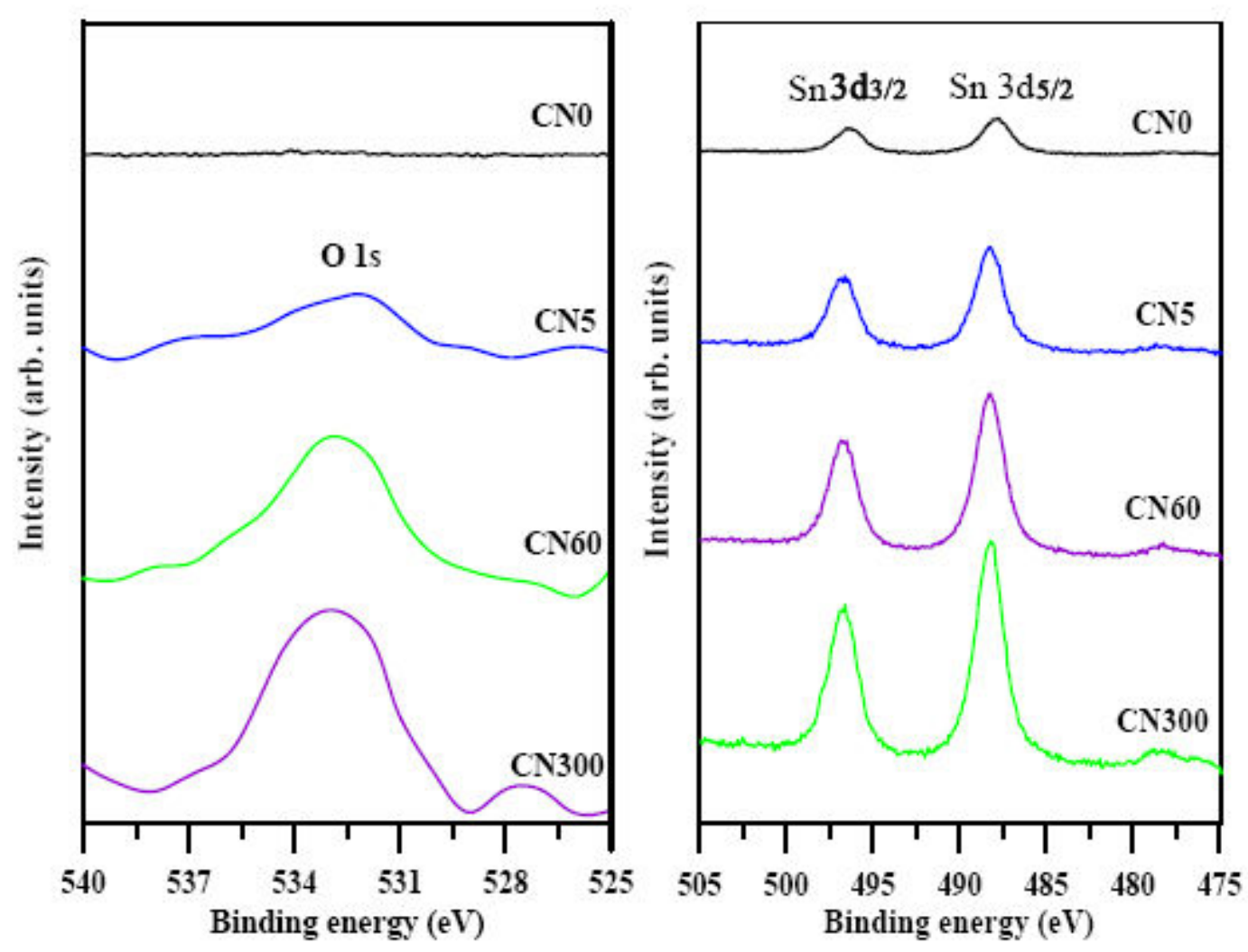

Fig. 3. O1s and $\mathrm{Sn} 3 \mathrm{~d}$ spectra of $\mathrm{SnO}_{\mathrm{x}}$ nanodots decorated CNTs by XPS.

Table 2. Relative peak area of $\mathrm{C} 1 \mathrm{~s}$ and $\mathrm{O} 1 \mathrm{~s}$ on the $\mathrm{SnO}_{\mathrm{x}}$ nanodots decorated CNTs with various oxidation treatment times.

\begin{tabular}{llll}
\hline Sample No. & C 1s (\%) & O 1s (\%) & Sn 3d (\%) \\
\hline CN0 & 92.9 & 4.8 & 2.3 \\
CN5 & 85.2 & 9.1 & 5.7 \\
CN60 & 83.1 & 9.9 & 7.0 \\
CN300 & 81.8 & 10.7 & 7.5 \\
\hline
\end{tabular}



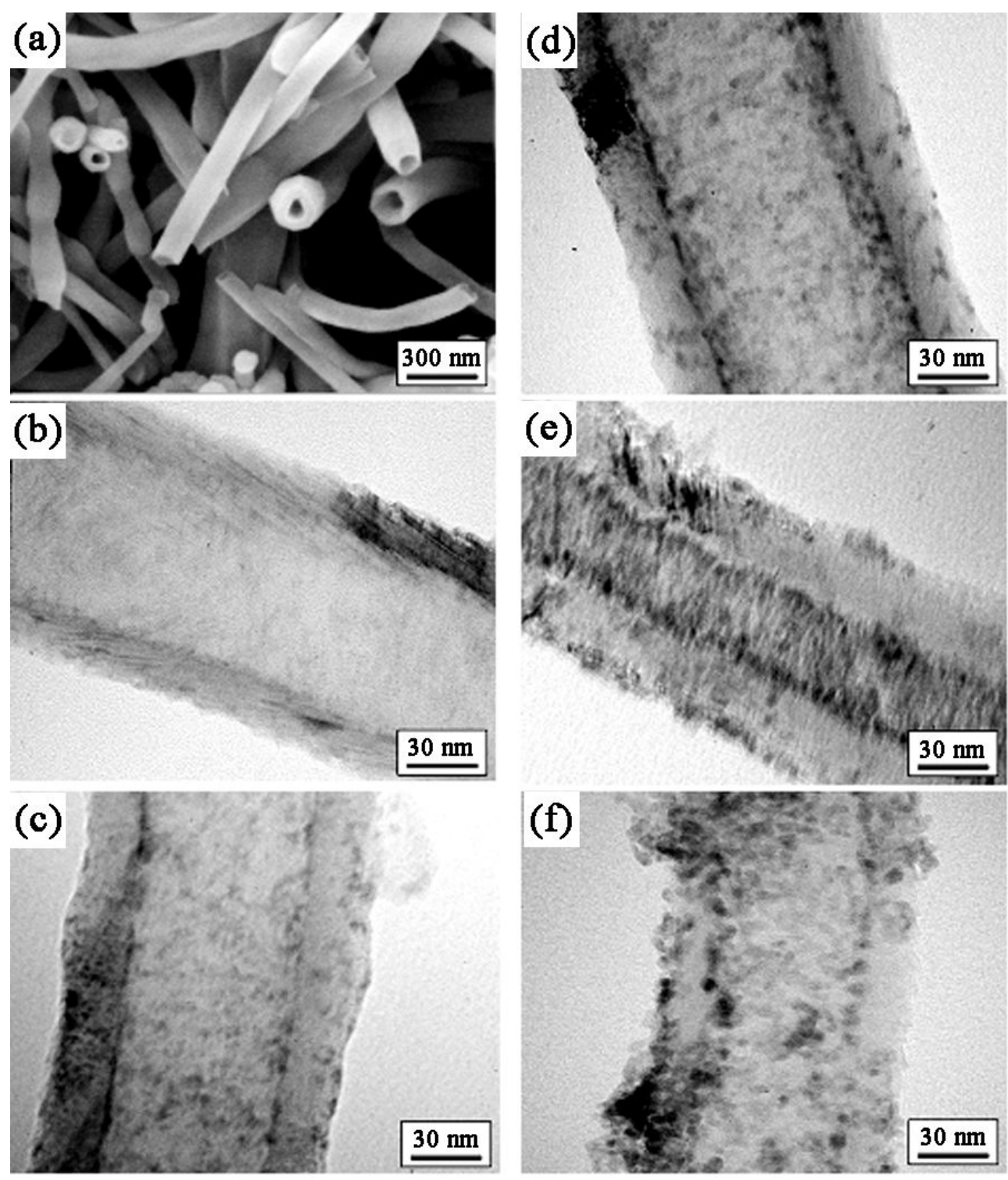

Fig. 4. (a) FE-SEM and (b) TEM images of the pristine CNTs. TEM images of $\mathrm{SnO}_{\mathrm{x}}$ nanodots on functionalized CNTs by immersing in a tin nitrate aqueous solution for (c) 0, (d) 5, (e) 60 and (f) 300 $\min$.

Figure 4 (a) and (b) show the FE-TEM images of the original CNTs with an average diameter of 90 $\mathrm{nm}$ and a wall thickness of $12 \mathrm{~nm}$. By ion exchange, the metal ions attached to the functional group on the surfaces of CNTs. In Table 2, the $\mathrm{SnO}_{\mathrm{x}}$ nanodots decorated CNTs without post-oxidation treatment (CN0) are composed of $2.3 \%$ of Sn, probably caused by the ion-adsorption of open-ended CNTs compared to Fig. 4 (c). The morphologies of the $\mathrm{SnO}_{\mathrm{x}}$ nanodots decorated CNTs are shown in Fig. 4 (c)-(f). It is observed that longer time-treatment results in greater- quantity nanodots. These images tell us that the mechanisms of the binding-metal oxides are affected not only by the oxidation level, but also by the ion-adsorption behavior on the open-ended nanotubes. With the higher oxidation level, the surface morphology of the $\mathrm{SnO}_{\mathrm{x}}$ nanodots decorated CNTs becomes more complicated. In the mixing step, functional groups on the surface (side wall) provide a stronger interaction with tin ions than that on the open-end. After assembling, adsorption, and sintering, $\mathrm{SnO}_{\mathrm{x}}$ nanodots with a 
mean diameter of $\sim 5 \mathrm{~nm}$ are well-dispersed on the surface of CNTs. The ionic interaction during the self-assembled process is schematic as follows,

$$
\begin{aligned}
& C \stackrel{\text { oxidization }}{\longrightarrow} C^{*} \\
& C^{*}+S^{4+} \stackrel{\text { ion-exchange }}{\longrightarrow} C^{*} S n
\end{aligned}
$$

where $\mathrm{C}$ represents the carbon-containing functional groups on the CNTs, $\mathrm{C}^{*}$ represents the carbon-containing functional groups on the CNTs with empty active sites, and $\mathrm{C}^{*} \mathrm{Sn}$ represents the carbon-containing functional groups on the CNTs with tin ions occupying the empty active sites. This reveals that the more the empty active sites created, the more tin ions attached based on the same immersing condition. In the final step of thermal treatment at $450{ }^{\circ} \mathrm{C}$ under an argon atmosphere, oxygen atoms from the oxygen-containing functional groups interact with bonding metal atoms, forming metal-oxide nanodots on the CNTs. Although the equations are schematic here, the actual reaction mechanisms have to further prove.

\section{Conclusions}

Uniformly dispersed $\mathrm{SnO}_{\mathrm{x}}$ nanodots with mean diameter $\sim 5 \mathrm{~nm}$ have been synthesized onto the functionalized surface of CNTs by a simple thermal oxidation at lower temperature $\left(250{ }^{\circ} \mathrm{C}\right)$ and a followed immersion in tin (IV) nitrate solution. Various oxidation levels lead to the change of O/C ratio and the distribution of the functional groups. XPS reveals that $\mathrm{O} / \mathrm{C}$ ratio gradually increases with the increasing of oxidation time. By deconvoluting, the peaks are mainly consisted of $\mathrm{C}-\mathrm{C}, \mathrm{C}-\mathrm{O}$, $\mathrm{C}=\mathrm{O}, \mathrm{O}-\mathrm{C}=\mathrm{O}$, and $\pi-\pi^{*}$ shake up functional groups. It is an efficiency method to synthesize metal-oxide nanodots/CNT hybrid material for further potential applications, e.g. fuel cell [4] and biosensor [6].

\section{Acknowledgment}

The authors would like to thank the National Science Council of Taiwan for financially supporting this research under Contract no. NSC 95-2221-E-034-020-MY2 and NSC 96-2221-E-034-006-MY2.

\section{References}

[1] V.N. Popov, Carbon nanotubes: properties and application, Mater. Sci. Eng. R 43 (2004) 61-102.

[2] J. Dinesh, M. Eswaramoorthy, C.N.R. Rao, Use of amorphous carbon nanotube brushes as templates to fabricate $\mathrm{GaN}$ nanotube brushes and related materials, J. Phys. Chem. C 111 (2007) 510-513.

[3] W. Fang, H.Y. Chu, W.K. Hsu, T.W. Cheng, N.H. Tai, Polymer-Reinforced, Aligned Multiwalled Carbon Nanotube Composites for Microelectromechanical Systems Applications, Adv. Mater. 17 (2005) 2987-2992.

[4] L. Li, Y. Xing, Pt-Ru nanoparticles supported on carbon nanotubes as methanol fuel cell catalysts, J. Phys. Chem. C 111 (2007) 2803-2808.

[5] C.V. Nguyen, K.J. Chao, R.M.D. Stevens, L. Delzeit, A. Cassell, J. Han, M. Meyyappan, Carbon nanotube tip probes: stability and lateral resolution in scanning probe microscopy and application to surface science in semiconductors, Nanotechnology 12 (2001) 363-367.

[6] K. Kerman, Y. Morita, Y. Takamura, M. Ozsoz, E. Tamiya, DNA-directed attachment of carbon nanotubes for enhanced label-free electrochemical detection of DNA hybridization, Electroanalysis 16 (2004) 1667-1672. 
[7] L. M. Yin, Y. Bando, and Y. C. Zhu, Controlled carbon nanotube sheathing on ultrafine InP nanowires, Appl. Phys. Lett. 84 (2004) 5314-5316.

[8] T. Laha, A. Agarwal, T. McKechine, and S. Seal, Synthesis and characterization of plasma spray formed carbon nanotube reinforced aluminum composite, Mater. Sci. Eng. A 381 (2004) 249-258.

[9] J. Shi, Y. Qin, W. Wu, X. Li, Z.X. Guo, D. Zhu, In situ synthesis of CdS nanoparticles on multi-walled carbon nanotubes, Carbon 42 (2004) 455-458.

[10] J. M. Haremza, M. A. Hahn, T. D. Krauss, S. Chen, and J. Calcines, Attachment of single CdSe nanocrystals to individual single-walled carbon nanotubes, Nano Lett. 2 (2002) 1253-1258.

[11] S. Ravindran, S. Chaudhary, B. Colburn, M. Ozkan, and C. S. Ozkan, Covalent coupling of quantum dots to multiwalled carbon nanotubes for electronic device applications, Nano Lett. 3 (2003) 447-453.

[12] T. Seeger, T. Kohler, T. Frouenheim, N. Grobert, M. Rühle, M. Terrones, Nanotube composites: novel SiO2 coated carbon nanotubes, Chem. Commun. 1 (2002) 34-35.

[13] S. W. Lee, W. M. Sigmund, Formation of anatase TiO2 nanoparticles on carbon nanotubes, Chem. Commun. 6 (2003) 780-781.

[14] Y. Gogotsi, N. Naguib, and J. A. Libera, In situ chemical experiments in carbon nanotubes, Chem. Phys. Lett. 365 (2002) 354-360.

[15] C. T. Hsieh and H. Teng, Influence of oxygen treatment on electric double-layer capacitance of activated carbon fabrics, Carbon 40 (2002) 667-674.

[16] D. Marton, K.J. Boyd, A.H. Al-Bayati, S.S. Todorov, J.W. Rabalais, Carbon nitride deposited using energetic species: a two-phase system, Phys. Rev. Lett. 73 (1994) 118-121.

[17] X.W. Liu, J.H. Lin, W.J. Hsieh, H.C. Shih, Morphology and characterization of highly nitrogenated, aligned, amorphous carbon nano-rods formed on an alumina template by ECR-CVD, Diam. Rela. Mater. 11 (2002) 1193-1199.

[18] S. Tang, N. Lu, J. K. Wang, S.K. Ryu, H.S. Choi, Novel effects of surface modification on activated carbon Fibers using a low pressure plasma treatment. J. Phys. Chem. C 111 (2007) 1820-1829. 